\title{
The cricopharyngeal sphincter in gastric reflux
}

\author{
P. S. HUNT, A. M. CONNELL, AND T. B. SMILEY \\ From the Department of Surgery, Queen's University of Belfast, and the Royal Victoria Hospital,'Belfast
}

SUMMARY This study was prompted by a clinical association noted between reflux oesophagitis and upper oesophageal disorders. Patients with reflux oesophagitis have been shown to have a significantly raised resting cricopharyngeal pressure. Patients with reflux oesophagitis $(36 \%)$ complaining of dysphagia localized to the throat also had a high resting cricopharyngeal pressure. Successful repair of a hiatus hernia restored the cricopharyngeal pressure to within the normal range. Four of the five patients studied who had a pharyngeal pouch also had a raised cricopharyngeal pressure.

Spasm of the cricopharyngeus may be a prerequisite for the development of a pharyngeal diverticulum (Belsey, 1966; Negus, 1957; Sutherland, 1962). On this view it has been suggested that spastic muscle fibres must be divided before repair of a pharyngeal diverticulum will be successful. It has also been observed that patients with a pharyngeal pouch and oesophageal web commonly have reflux oesophagitis and/or a hiatus hernia. Twenty-eight of 30 patients with a pouch and 23 of 29 with a web had these associated findings (Smiley, 1967), suggesting a relationship between the pathophysiology of the proximal and distal oesophagus. This investigation confirms that raised cricopharyngeal pressures exist in patients with lower oesophageal disorders.

\section{Materials and Methods}

Studies of oesophageal motility were performed on 78 persons divided into five groups (Table I). Sixteen people who had no known gastrointestinal lesion volunteered to have pressure studies and served as a control group (group 1). Forty-seven patients with gastroesophageal reflux, which had been proved by the presence of heartburn and oesophagitis seen at oesophagoscopy, formed groups 2 and 2a. These patients' symptoms were sufficiently severe to warrant con- sideration of surgical treatment, and were included even if a hiatus hernia was not observed radiologically or if obvious gastroesophageal reflux was not seen at oesophagoscopy. Seventeen of these patients $(36 \%)$ with heartburn and oesophagitis admitted difficulty in swallowing, localized to the neck, which they usually described as food sticking in the throat (group 2a). These patients had more severe heartburn than the 30 without dysphagia (group 2).

A further 10 patients had complained of heartburn for many years, but more recently the symptoms had disappeared to be replaced by dysphagia localized to the lower sternum. They had all developed a distal oesophageal stricture and were placed in group 3 . Group 4 comprised nine patients studied before, and six months after, a successful repair of a hiatus hernia. At the time of postoperative study they were free of symptoms of gastroesophageal reflux. Group 5 consisted of five patients with a pharyngeal pouch.

With the exception of the control observations, studies were done as part of the hospital diagnostic service in oesophageal disease. The patients did not have to fast before manometric studies taken in the supine position. Two to $3 \mathrm{ml}$ of $4 \%$ topical xylocaine was sprayed to nose and throat 15-20 minutes before each study. There is no evidence that this local xylocaine affected the comparative results. Three water-filled polyvinyl catheters, with an internal diameter of $1.5 \mathrm{~mm}$ 


\begin{tabular}{|c|c|c|c|c|c|c|c|}
\hline \multirow{3}{*}{ Group } & \multirow{3}{*}{$\begin{array}{l}\text { Number of } \\
\text { Patients }\end{array}$} & \multicolumn{4}{|c|}{ Cricopharyngeal Sphincter } & \multirow{2}{*}{\multicolumn{2}{|c|}{$\frac{\text { Pharynx }}{\text { Swallowing }}$}} \\
\hline & & \multirow[t]{2}{*}{ Length (cm) } & \multirow{2}{*}{$\begin{array}{l}\text { Mean Resting } \\
\text { Pressure } \\
\left(\mathrm{Cm} \mathrm{H}_{2} \mathrm{O}\right)\end{array}$} & \multicolumn{2}{|l|}{ Swallowing } & & \\
\hline & & & & $\begin{array}{l}\text { Duration of } \\
\text { Relaxation } \\
\text { (sec) }\end{array}$ & $\begin{array}{l}\text { Contraction } \\
\text { Pressure } \\
\left(\mathrm{cm} \mathrm{H}_{2} \mathrm{O}\right)\end{array}$ & $\begin{array}{l}\text { Contraction } \\
\text { Pressure } \\
\left(\mathrm{cm} \mathrm{H}_{2} \mathrm{O}\right)\end{array}$ & $\begin{array}{l}\text { Duration of } \\
\text { Contraction } \\
\text { (sec) }\end{array}$ \\
\hline \multirow{5}{*}{$\begin{array}{l}1 \text { Control } \\
2 \text { Gastroesophageal } \\
\text { reflux } \\
\text { 2a Cervical } \\
\text { dysphagia } \\
3 \text { Distal oesophageal } \\
\text { stricture } \\
4 \text { After repair of } \\
\text { hiatus hernia } \\
5 \text { Pharyngeal pouch }\end{array}$} & 16 & 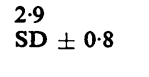 & $\begin{array}{l}14 \cdot 6 \\
S D \pm 7 \cdot 3\end{array}$ & 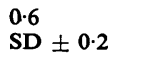 & 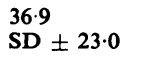 & 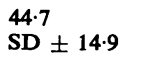 & 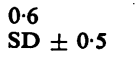 \\
\hline & 30 & $3 \cdot 3 \pm 1 \cdot 0$ & $32 \cdot 1 \pm 11 \cdot 2$ & $0.9 \pm 0.3$ & $42 \cdot 1 \pm 17 \cdot 2$ & $47 \cdot 3 \pm 15 \cdot 0$ & $0.6 \pm 0.3$ \\
\hline & 17 & $3 \cdot 1 \pm 1 \cdot 3$ & $37.9 \pm 15 \cdot 8$ & $0.9 \pm 0.6$ & $37 \cdot 3 \pm 24 \cdot 3$ & $44 \cdot 7 \pm 19 \cdot 3$ & $0.8 \pm 0.3$ \\
\hline & 10 & $2 \cdot 5 \pm 0.5$ & $12 \cdot 4 \pm 4 \cdot 1$ & $0.7 \pm 0.4$ & $31 \cdot 0 \pm 8 \cdot 5$ & $49 \cdot 5 \pm 20 \cdot 1$ & $0.8 \pm 0.3$ \\
\hline & $\begin{array}{l}9 \\
5\end{array}$ & $\begin{array}{l}4.1 \pm 1.3 \\
6.4 \pm 0.5\end{array}$ & $\begin{array}{l}21 \cdot 4 \pm 5 \cdot 0 \\
41 \cdot 0 \pm 27 \cdot 2\end{array}$ & $\begin{array}{l}0.9 \pm 0.2 \\
1 \cdot 2 \pm 0.4\end{array}$ & $\begin{array}{l}47 \cdot 5 \pm 38 \cdot 2 \\
40 \cdot 2 \pm 27 \cdot 8\end{array}$ & $\begin{array}{l}45 \cdot 0 \pm 17 \cdot 1 \\
60 \cdot 0 \pm 18 \cdot 7\end{array}$ & $\begin{array}{l}0.5 \pm 0.1 \\
0.7 \pm 0.2\end{array}$ \\
\hline
\end{tabular}

Table I The mean and standard deviations of aspects of cricopharyngeal and pharyngeal pressure profiles
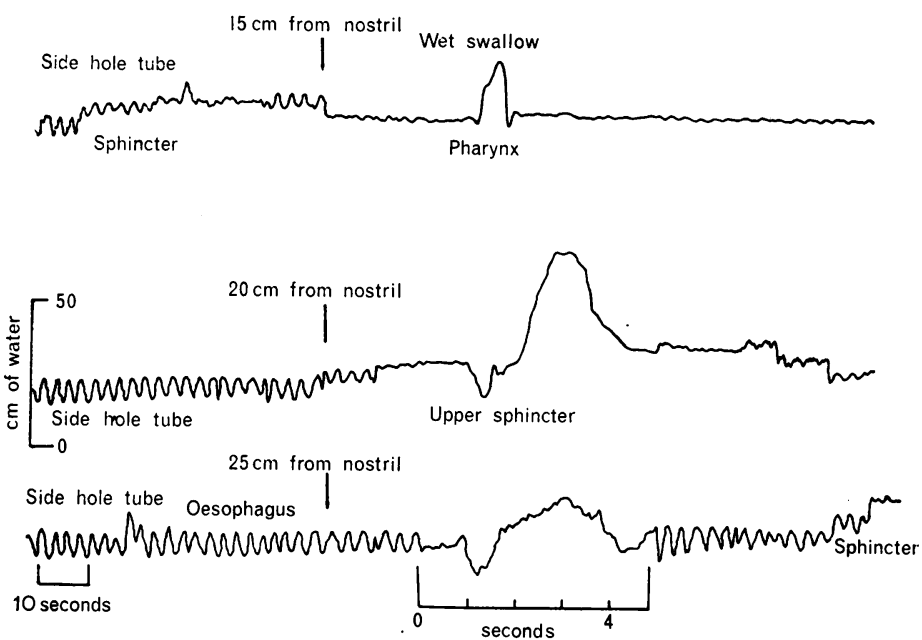

Fig. 1 A normal intraluminal pressure recording of the upper oesophagus and pharynx in a patient after repair of an inguinal hernia and with no evidence of oesophageal disease. (On the left hand side of the figure the upper channel is a recording from the upper sphincter. On the right hand side the middle channel is a recording from the upper sphincter whereas the upper aperture has moved into the pharynx.)

and distal side holes, were bound with the recording apertures $5 \mathrm{~cm}$ apart, and passed through the nose into the oesophagus. Intraluminal pressures from the three positions were simultaneously transmitted to external transducers, the signals amplified and displayed on a direct writing recorder (Schwarzer, Munich). The polyvinyl tubes were withdrawn step by step from the upper oesophagus into the pharnyx giving a pressure profile across the cricopharyngeal sphincter from oesophagus to pharynx.

The pressure at the end expiratory phase of respiration was selected for all measurements. This point is the longest period of stable pressure in the respiratory cycle (Fyke and Code, 1955). The end expiratory pressure in the upper oesophagus was chosen as the zero base line so that the value of cricopharyngeal resting tone would ${ }_{0}^{\omega}$ then indicate the resistance to reflux.

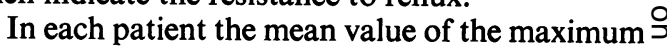
resting cricopharyngeal tone, the length of the sphincter, and the duration of relaxation preced-ing the swallowing wave were measured. The mean pressure and duration of contraction of the $\vec{\theta}$ pharyngeal swallowing pressure were also re-. corded.

\section{Results}

Immediately following deglutition, in all groups, pressure in the cricopharyngeal zone dropped to rise abruptly as the pressure created by the pharyngeal constriction involved the upper sphincter. A normal recording is seen in Figure 1. There was no difference between the groups in regard to the pattern of the pressure response of $\vec{\sigma}$ the pharynx following deglutition, and in each case there was a rise in pressure across the $\delta$ cricopharyngeal sphincter. However, the magnitude of the pressure across the sphincter was $ᄋ$ greater in patients with reflux oesophagitis (Figure 2).

\section{CONTROL SUBJECTS (GROUP 1)}

The mean resting cricopharyngeal tone in 16 ल normal individuals studied was $14.6 \pm 7.3 \mathrm{~cm}$ О of water, and the mean length $2.9 \pm 0.8 \mathrm{~cm}$. The duration of relaxation preceding the peri- $\mathbb{\Phi}$ staltic wave was $0.6 \pm 0.2 \mathrm{sec}$, and the mean height of the wave was $36.9 \pm 23 \mathrm{~cm}$ of water. The mean duration of pharyngeal contraction on swallowing was $0.63 \pm 0.5 \mathrm{sec}$ and the mean pressure was $44.7 \pm 14.9 \mathrm{~cm}$ of water (Table I).

PATIENTS WITH OESOPHAGITIS (GROUP 2) Patients with reflux with or without cervical dysphagia had a greater resting pressure in the cricopharyngeal sphincter than the control group $(P<0.001)$ (Table I, Figure 3). Other parameters of their sphincter function did not differ. 

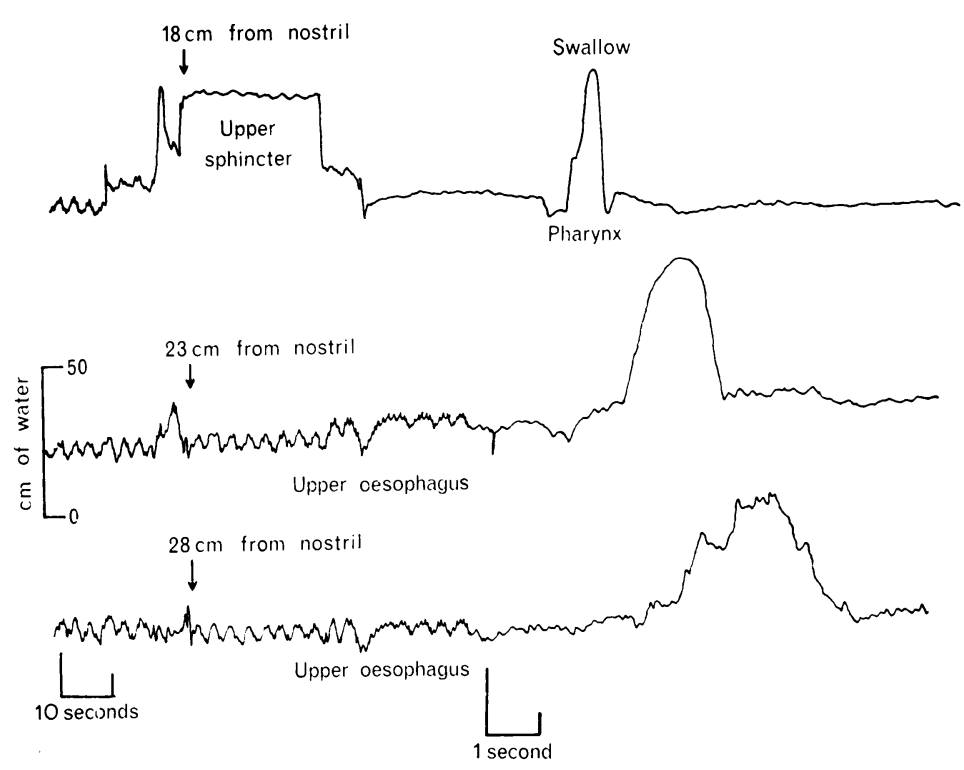

Fig. 2 The intraoesophageal pressure recordings of a patient with reflux oesophagitis. (On the left hand side of the figure the upper channel is a recording from the cricopharyngeal sphincter. On the right hand side it has been pulled to record from the pharynx.)

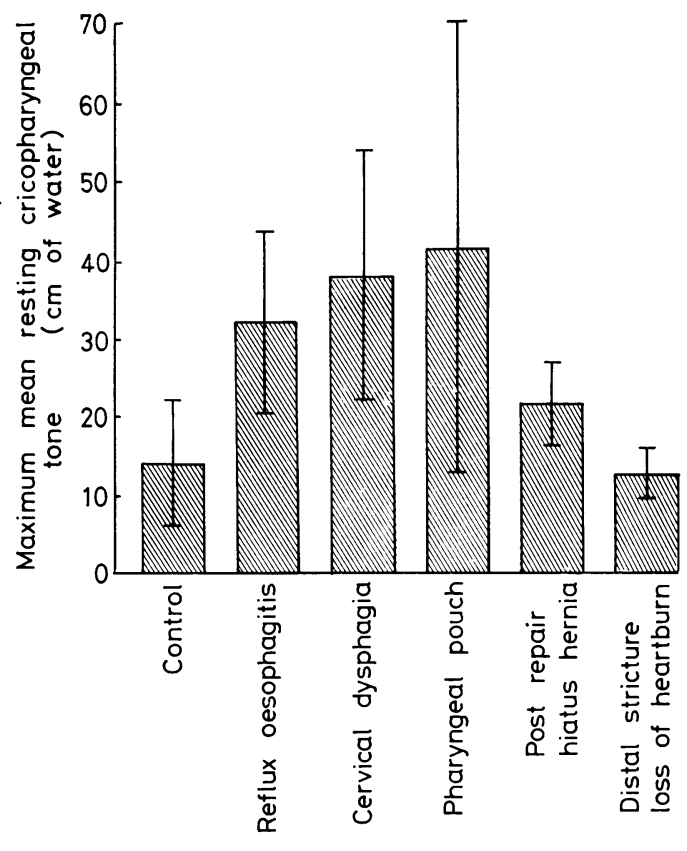

Fig. 3 Mean and standard deviation of the resting cricopharyngeal pressures in patients with oesophageal disorders compared with a control group.

\begin{tabular}{lll}
\hline Patient & $\begin{array}{l}\text { Before Repair } \\
\left(\mathrm{cm} \mathrm{H}_{2} \mathrm{O}\right)\end{array}$ & $\begin{array}{l}\text { After Repair } \\
\left(\mathrm{cm} \mathrm{H}_{2} \mathrm{O}\right)\end{array}$ \\
\hline 1 & 50 & 30 \\
2 & 45 & 18 \\
3 & 45 & 20 \\
4 & 43 & 28 \\
5 & 40 & 15 \\
6 & 38 & 18 \\
7 & 32 & 24 \\
8 & 30 & 16 \\
9 & 22 & 24 \\
Mean (P < 0.01) & $38 \cdot 3 \pm 8.8$ & $21 \cdot 4 \pm 5 \cdot 0$ \\
\hline
\end{tabular}

PATIENTS WITH REPAIR OF HIATUS HERNIA (GROUP 4)

Following repair of a hiatus hernia the resting cricopharyngeal sphincter pressure was lower than in unoperated patients with oesophagitis $(\mathrm{P}<0.01)$. Resting pressures were decreased by 20 centimetres of water or more after repair in five of nine subjects tested before and after surgery (Table II).

\section{PATIENTS WITH PHARYNGEAL POUCH (GROUP 5)}

Four of the five patients with a pharyngeal pouch had a very high resting cricopharyngeal pressure. These four patients also had an elongated sphincter although possibly because of the small numbers, it was not possible to show any significant differences between these patients and other groups. The mean and standard deviation of this group is included in the comparison of cricopharyngeal pressures shown in Figure 3. There were no significant differences between the groups
Table II Mean maximum resting cricopharyngeal sphincter pressure before and after repair of hiatus hernia

of patients in respect of the duration or strength of swallow measured in either the pharynx or the sphincter (Table I).

\section{Discussion}

The control values in this study were similar to the pressures obtained by Atkinson, Kramer, Wyman, and Ingelfinger (1957) but are lower than those of another north American investigation (Fyke and Code, 1955) which used a small pressure transducer within the oesophagus.

The finding of a raised cricopharyngeal tone in reflux oesophagitis confirms an observation sometimes made at oesophagoscopy. It is often 
difficult to pass the instrument into the upper oesophagus when gastric juice may be seen welling through the upper sphincter into the lower oesophagus. Reflux of barium in patients with incompetence of the cardia usually is halted at the cricopharyngeus and does not proceed into the mouth or pharynx.

The cause of cervical dysphagia in reflux oesophagitis is not clearly established in this investigation. These patients have high resting cricopharyngeal sphincter pressures, but there is adequate relaxation preceding peristalsis and no detectable incoordination of activity, nor is there any difference in the pressure profile following swallowing. However, since the heartburn is severe in these patients it is possible that the increased resting pressure represents a response to the presence of irritant material in the lower oesophagus which prevents its reflux into the pharynx.

Resistance to passing an oesophagoscope has also been found in patients with oesophageal pouch and web (Smiley, 1967; Smiley, McDowell, and Costello, 1963). In the five patients with pouch studied in this series, four had a high resting upper sphincteric tone. One patient with a large pouch had a low resting tone. This differs from the findings of Kodicek and Craemer (1961), who noted that only one patient with pharyngeal pouch had a pressure outside the normal range.
It may be that the resting pressure depends on the extent to which the existence of the pouch has disrupted the normal muscular anatomy of the sphincter. Clagett (1963) has presented clinicat evidence that a pharyngeal pouch develops in a area of congenital or acquired weakness. Never? theless, it may be that the increased cricos pharyngeal pressure in the presence of reflu芩 may be a factor in the eventual development of pouch in such predisposed individuals (Localio and Stahl, 1968).

References

Atkinson, M., Kramer, P., Wyman, S. M and Ingelfinger, F (1957). The dynamics of swallowing. I: normal pharyngeat mechanisms. J. clin. Invest., 36, 581-588.

Belsey, R. (1966). Functional disease of the oesophagus. J. thoract cardiovasc. Surg., 52, 164-188. Clagett, O. T. (1963). Pharyngo-esophageal diverticula. Surg. Clin $\omega_{\omega}^{\omega}$
N. Amer., 43, $1165-1169$.

Fyke, F. E., Jr., and Code, C. F. (1955). Resting and deglutitioß pressures in the pharyngo-esophageal region. Gastroenterology, 29, 24-34.

Kodicek, J., and Craemer, B. (1961). A study of pharyngeaf pouches. J. Laryng., 75, 406-411.

Localio, S. A., and Stahl, W. M. (1968). Diverticular disease of the alimentary tract. II. The esophagus, stomach, duoeo denum and small intestine. Curr. Probl. Surg., 3-47.

Negus, V. E. (1957). The etiology of pharyngeal diverticula: Bull. Johns Hopk.Hosp., 101, 209-223.

Smiley, T. B. (1967). Unpublished data.

Smiley, T. B., McDowell, R. F. C., and Costello, W. T. (1963) Sideropenic dysphagia and hiatus hernia. Lancet, 2, 7-11

Sutherland, H. D. (1962). Cricopharyngeal achalasia. J. thoraci cardiovasc. Surg., 43, 114-126. 